\title{
Erratum to: Networks: a generic theory for hydrology?
}

\author{
Bellie Sivakumar
}

Published online: 23 September 2014

(c) Springer-Verlag Berlin Heidelberg 2014

\section{Erratum to: Stoch Environ Res Risk Assess (2014)}

DOI 10.1007/s00477-014-0902-7

In the original article in the text paragraph under Fig. 2 the mean clustering coefficient values listed were incorrect. The correct version is:
"The mean clustering coefficient of the entire network is 0.67 and 0.70 for these two cases, respectively." Everything else in the article remains correct.

The online version of the original article can be found under doi:10.1007/s00477-014-0902-7.

B. Sivakumar $(\square)$

School of Civil and Environmental Engineering, The University of New South Wales, Sydney, NSW 2052, Australia

e-mail: s.bellie@unsw.edu.au

B. Sivakumar

Department of Land, Air and Water Resources, University of California, Davis, CA 95616, USA

e-mail: sbellie@ucdavis.edu 